\title{
INFORMATION LITERACY: TEACHER'S PERSPECTIVES OF THE INFORMATION PROCESS
}

\author{
Judy O'Connell \\ Curriculum Coordinator \& Teacher Librarian \\ Bethlehem College \\ 7 Glenelg Place \\ Beecroft NSW, Australia \\ E-mail: judy@geko.net.au \\ James Henri \\ Senior Lecturer \\ Department of Information Studies \\ Charles Sturt University, Australia \\ E-mail: jhenri@golum.riv.csu.edu.au
}

\begin{abstract}
Teaching within a student-centered paradigm in an information society means accepting the responsibility of teaching for the acquisition of integrated information habits and fully adaptable lifelong information skills. Information literacy is critical, yet not enough has changed in education to make in an understood part of the pedagogy of the classroom. Australian studies point the way for developing a sense of clarity for practical change.
\end{abstract}

\section{INTRODUCTION}

Without a doubt, all of us, as teachers, are only too aware that being an educator today means operating in an environment of reform. This environment is not just an environment of curriculum reform, but it is also an environment of startling technological reform. In such a context our charter as teacher librarians, and custodians of the library, has been to facilitate the integration of literacy and information skills into the curriculum. This we have been able to do because of our unique combination of professional skills-educator and information professional.

As custodians of the school library we have been quite comfortable with literacy for a what seems a long time. Books are at the heart of literacy and learning. Yet, in another time frame, the general use of school libraries in school education has only really emerged in the last two or three decades, while the general bibliothecal model for education can chart its establishment back as far as the industrial revolution and the invention of the printing press.

A few centuries later it was promotion of literacy and learning strategies and the incorporation of these strategies into the research process which led to a conceptualization of the cognitive and information skills being used.

Articulation of the information skills and the development of information literacy models match the emergence of the technological era and the phenomenal growth in knowledge and resultant information available in the world today.

We know that our students must learn how to access, process, manage and communicate information-if you like-to become architects of information. In our role as teachers and information professionals we already know that if we restructure the curriculum to include the concept of information we will not have to worry about how the technology fits. We know that it is possible for technology to become almost transparent and seamless in the learning process for students and teachers. 
Is it too dramatic to say that we are in the throes of a traumatic period of change? Did if people during the print revolution felt traumatized as they were creating history? Who welcomed change vigorously and with urgency?

The question at the heart of our very own period of change can be more easily put into context by some simple observations. When you return to school look about your classrooms and ask yourself: "Has this teacher recognized the need for a shift in the pedagogy of the classroom-driven by technology? If there is an awareness, is he/she managing the change with all the implications that that change carries for information literacy?"

As we look across classrooms in Australia and Canada, where we have had very active programs in place to foster integration of information skills for many years, it is likely that some of us are still seeing poor outcomes and that we will, again, question why it is that there are still so many instances where teaching strategies have been ineffective in fostering information literacy and lifelong learning skills.

\section{INFORMATION LITERACY}

Information is a valuable and essential resource in an information society. Thus, developing skills for acquiring and using information are critical activities. If we recognize that effective teaching of higher order cognitive and problem-solving skills cannot be achieved with a naive view of information use and users (Liesener, 1985), then we can easily accept that the taxonomy of the research process for school students is a thinking process requiring skills, strategies and activities which act as blueprints for research and so help to develop powerful, lifelong information skills (Stripling \& Pitts, 1988).

In the 1980s and 90s the attempt to define these skills, processes and patterns of learning as "information literacy" serves to highlight the impact of information and technology on education; the importance of effective use of information; the need for well-developed skills for seeking, obtaining and using information; and the requirement for technical and cognitive skills to facilitate the process.

The Information Process (Table 1), from the document Learning for the future: Developing information services in Australian Schools (1993) shows quite clearly the multiple aspects of information literacy which must be considered and incorporated into our classroom teaching practice. This model describes an information process as a core activity, with the interactive skills of literacy and critical thinking as integral to the process of collecting, analyzing and organizing information across all learning areas. The model demonstrates that information literacy, and the information process, can provide the conceptual framework for the development of educational models and new curricular concepts for systematically addressing learning in an information-rich society.

\section{EDUCATION IN THE 20TH CENTURY}

With such a model of information literacy we are looking at the development of a new paradigm for collaborative education in what is now also a technological environment, which incorporates and promotes literacy, supports both novice and expert understandings of information seeking and information use, and which will be sufficiently advanced to take account of such things as key interface and interaction responses to working with various digital repositories of information. Unless we make information literacy the focus, adaptive hypermedia and technology in all their shapes and forms will only be further passive raw material rather than dynamic tools for creativity, communication, and independent learning.

This change and challenge in education leads us to question the roles and responsibilities of teachers in our schools. Whatever the nature of the discussion, technology figures in some way or other. yet our classrooms should not be driven by technology. Rather, they should be driven by teachers shaping and applying technology in creative and meaningful ways, so that the learning environment develops the individual student's ability to generate and communicate knowledge, thoughts and ideas-using technology as seamlessly as any bibliographic resource. This demands the presence of teachers acting as mediators who offer navigational assistance, support or guidance to learners in order to optimize their learning experiences. 


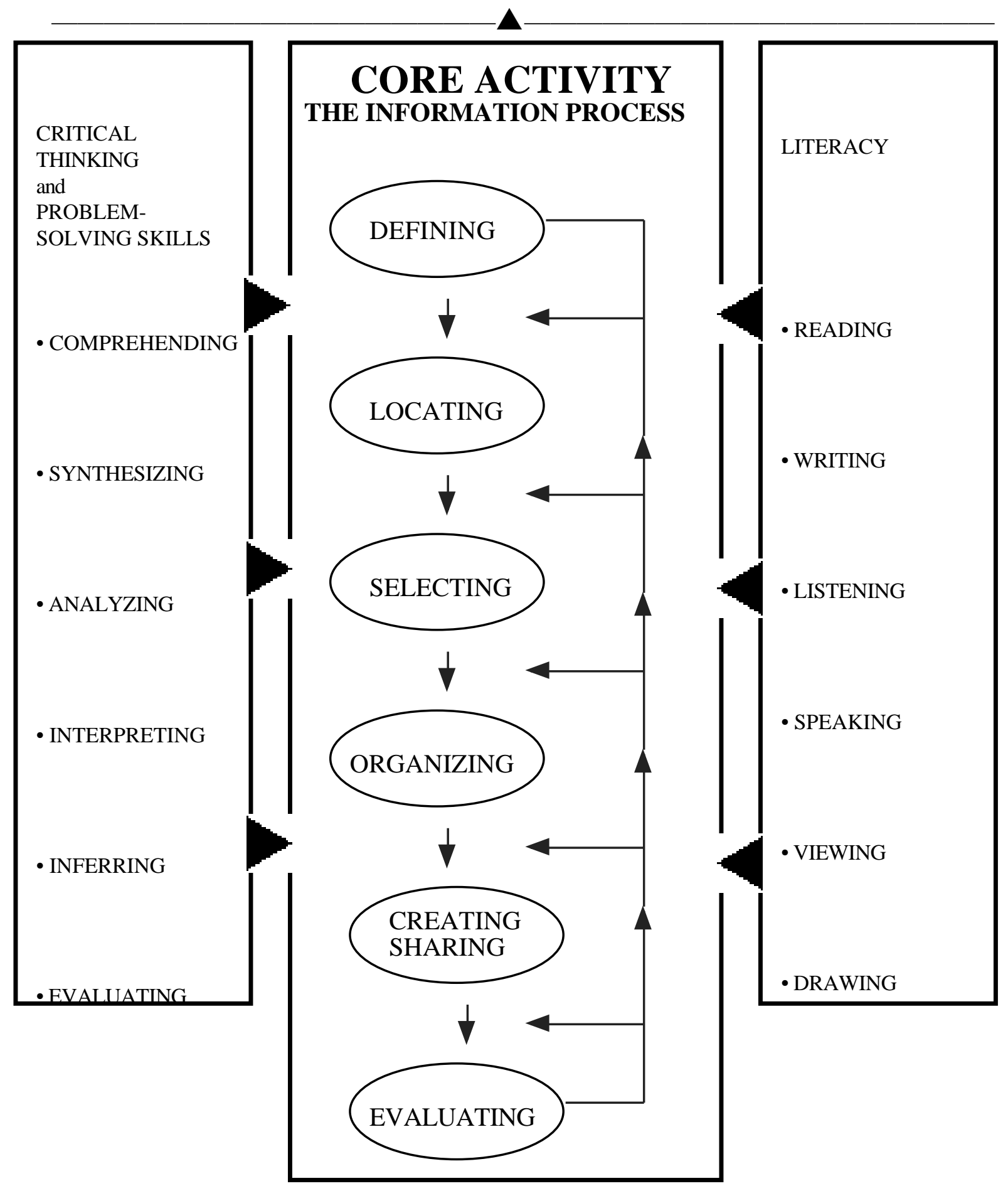

Table 1: The Information Process ${ }^{3}$

${ }^{3}$ ASLA \& ALIA, (1993). Learning for the future: Developing Information services in Australian schools. Carlton: Curriculum Corporation. 


\section{TEACHER'S INFORMATION SKILLS}

The work of Carol Kuhlthau (1993) has shown that seeking meaning is a constructive process, and one that uses information as a way of learning and finding meaning (Table 2). Such a constructive process of learning involves individuals in relating new information to what they already know and extending that knowing to form new understandings. She presents a holistic model of the information search process which incorporates three realms common to each stage of the process: the affective (feelings); the cognitive (thoughts); and the physical (actions).

By examining the patterns of experience of those involved in the process of seeking meaning Carol Kuhlthau's work has been able to highlight key areas of concern in the pedagogical problem of developing a multi-faceted information literacy in our school students.

One area of concern identified is the conflict between the students' understanding of their information seeking task and their actual experiences in the process of information seeking.

Another identified area of concern involves the role of the "mediator" as a dynamic part of the information seeking process. The mediator offers process strategies for exploring and formulating in order to enable students to learn how to learn.

If we are willing to acknowledge that the teacher in the classroom must act in the critical role of 'mediator' in the information seeking process, then Rogers (1994) review of research on teaching information skills will begin to ring alarm bells. His review highlights the lack of information skills of teachers which thereby stand in the way of skills acquisition by pupils. What is at the core of the problem is the teacher/student interaction taking place in the learning process.

\section{AUSTRALIAN STUDY}

Education today demands classroom teachers who can:

- model good practice in education programs that teach students to become aware of their own process of learning from a wide variety of bibliographic and technological sources of information;

- act effectively as mediator by identifying the zone of intervention for each student or class;

- carry out teaching only in those areas where the student can learn successfully from

a variety of sources.

These are the teachers who will assist our students to bridge the gap between the demands of today's and tomorrow's information society.

Before we can integrate fully-fledged information literacy strategies into the mainstream of the educational process in Australian schools and have them become part of the common pedagogy of our teachers, research is telling us that we must first critically examine teachers' perspectives of the information-seeking process. We must more closely examine the relationship of this perspective to classroom expectations. We must recognize and take into account the zone of comfort with the various aspects and stages of the information search process which each teacher has.

When we begin to take these factors into account we are more likely to be able to respond to the causes of conflict outlined by Carol Kuhlthau (1993) relating to student experience and effectiveness of teachers working as mediators.

As part of a whole school review of teaching and learning at Bethlehem College, Ashfield, Australia, a study was designed to explore these issues. In particular, this study sought to examine how a teacher's personal experience of the process of seeking information predicates teaching of the information search process to students. 


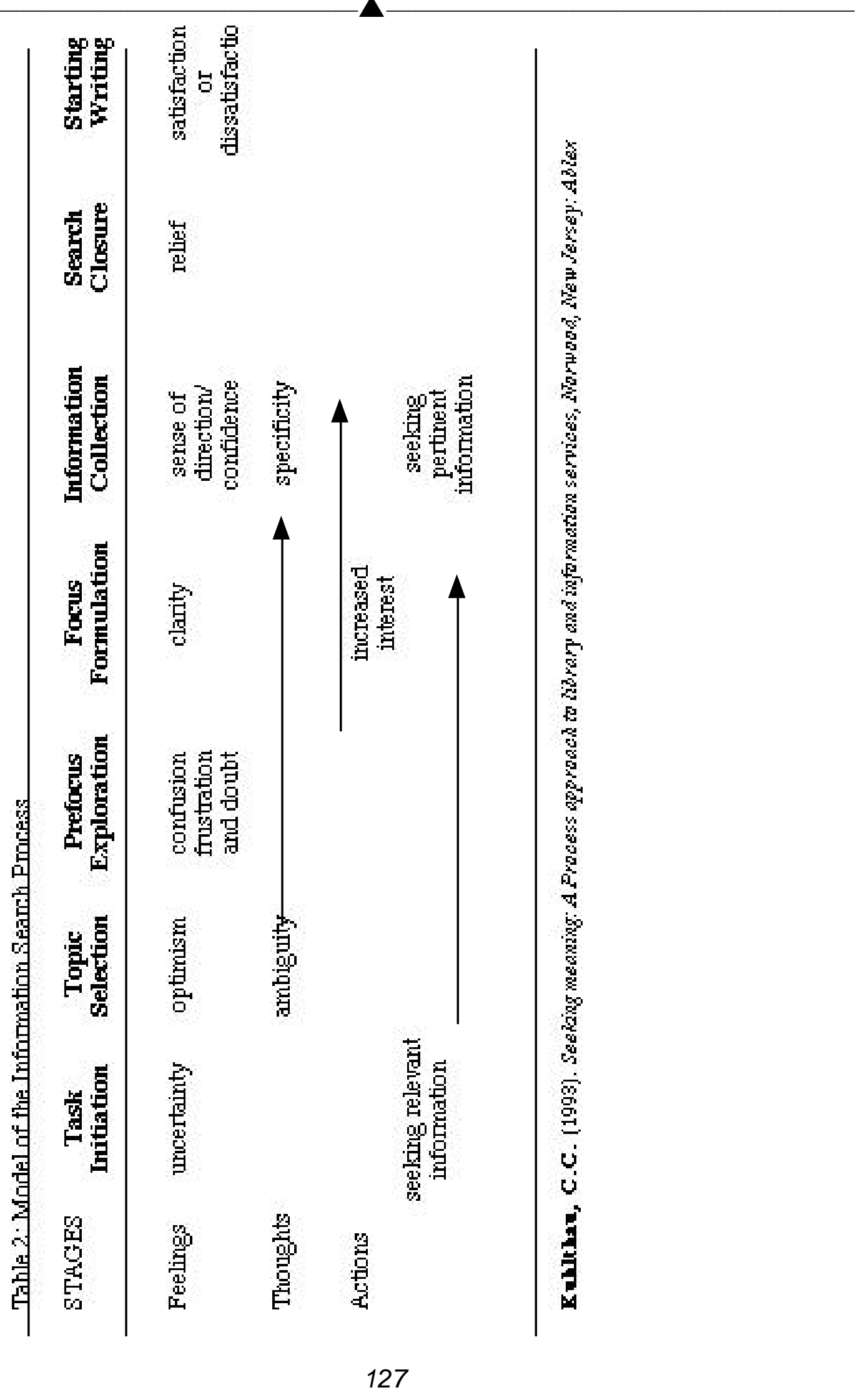


In essence, if we want our teachers to act successfully as mediators for information literacy and learning, shouldn't we be aware of our teachers' personal perspectives of information literacy and the context for learning they create for their students? How do teachers' perspectives of the information search continuum match or determine phases of information construction expected of students? If we ask teachers to rate their own expertise and zone of comfort within a multi-faceted approach to information seeking, how will this relate to their expectations for their students?

These and many other aspects in the study sought to provide an overview of the dynamic process of teaching in an information literate classroom and the personal perspectives and competencies that modify or empower the process, so as to develop a clearer direction for molding and developing the role of teacher as mediator and dynamic facilitator of the information seeking and learning process.

While there are many externally imposed influences on the interactions taking place in the classroom, it is the significance of teachers' personal perspectives of the information search process and the likely impact of these perspectives on the pedagogy of the classroom for which we should make due allowance. The Bethlehem study included an investigation of teachers' perceived competence with various sources of information and technology alongside their expectations for their students, adding depth to a discussion about education which is becoming more student-centered and increasingly technology-based.

It is the key issues raised by this investigation that provide a valuable focus for discussion and which are offered as points for consideration or for investigation in your own schools.

\section{Discovering Teachers' Perspectives of the Information Search Process}

Perceptions are difficult to observe. Personal perceptions of the information process and the way that those perceptions color or influence a teacher's expectations for the information continuum of their students can be even more illusive. Yet they underpin the nature and quality of interactions taking place in the classroom.

Recognizing this, the Bethlehem study drew on the work of Carol Kuhlthau (1993) by adapting her Perceptions Questionnaire as a way of eliciting understandings in this domain. It formed the first part of an extensive survey questionnaire used at Bethlehem College.

Section two of the Teacher Survey questionnaire examined teachers' perceptions of the information literacy continuum for students; teachers' preferences for the information search behavior for students in their classes based on the teachers' perceptions section; investigation of teachers' knowledge and confidence with bibliographic and technological sources of information in comparison with the teachers' sense of relevance and importance of the same source of information for their students.

The third and fourth sections of the survey, though not included here, explored the planning and research strategies used by teachers, including lesson preparation methodology, involvement with collaborative processes, and the professional dimension of education practice such as professional development, preferred or most often used sources of information, and involvement with professional activities such as organization, magazines, conferences, etc..

The validity of the investigation was corroborated by an interview schedule with key Faculty Coordinators in the school. The interviews followed a discussion format designed to explore the personally understood meanings behind key focus questions of the Teacher Survey and to provide an opportunity for hearing individual opinion and personal comment.

\section{Bethlehem Teachers' Mental Model of the Information Search Process}

The Perceptions Questionnaire (Section one of the Teacher Survey) provided a construct with which to articulate our teachers' perspectives of the information search process for themselves. By assessing preference in a qualitative way, using a four-point Likert-scale, but by collapsing responses into a match or non-match within the Kuhlthau framework, the survey data was utilized to provide a "snap-shot," or mental model of the information research process, with an immediate evaluation of the caliber of the mental model being expressed by these teachers. The findings offer some challenges for consideration. 
Focus formulation. This is central to the information seeking process and integral to the process of knowledge construction. A focus cannot be clear from the beginning but is refined or begins to emerge as part of an information search process. Early in the search information can be confusing, and uncertainty marks the construction process.

Yet, 80.6 percent of the teachers expressed a view that a focus is clear from the beginning of a search, with only 72.2 percent of teachers acknowledging that information is often confusing. While the teachers are aware of the dynamic nature of information seeking, they nevertheless believe that they know what information they want before they begin the information search process and generally do not recognize the sense of uncertainty and confusion that often accompanies the information seeking process.

This finding does, of course, support the Eisenberg and Brown (1992) assertion that all information skills models are largely the same and that clarity is essential early in the task definition stage. However, Kuhlthau's (1993) explanation of the information seeking process, based on a series of longitudinal research studies, has shown that we cannot ignore the affective domain. Her model of the information search process is unusual for acknowledging the sense of uncertainty and confusion that accompanies the research process, including the critical phase of focus formulation. For work in our Australian schools her model clearly makes a distinction between Defining as the first step in the information skills process and Focus formulation as an early phase of the process, operating within both the affective and cognitive domain. We cannot lock our students into a mode where they must define first, before utilizing information, as there is then no scope for the inevitable confusion that comes before clarity.

Sequence. Seeking and using resources involves physical tasks which enhance or hinder the affective and cognitive process of construction and will influence the formulation of the focus. Procedures for gathering information can vary, but the 'sophisticated' researcher will gather and organize information over a period of time from a variety of resources, commonly taking few notes or limited points at the beginning of the information search process (Kuhlthau, 1993). A naive approach to sequence is more likely to be a sign of a confused researcher, an inexperienced researcher, or a researcher in a rush.

The teachers showed themselves to be regular users of libraries, accustomed to the research process. Nevertheless, they exhibited all the signs of a naive approach, with such strategies demonstrated as making comprehensive notes or extensive photocopies to analyze and synthesize later, while also relying on the catalogue to provide access points to all information required. Are our teachers always researchers in a hurry?

Cognitive strategy. The information search process involves cognitive as well as physical actions in selecting information pertinent to a focus. Cognitive organizational strategies (goal setting, strategic planning, monitoring, evaluation and revision) and cognitive learning strategies (knowing how to learn; getting more knowledge in a familiar subject; reconfiguring knowledge already possessed; seeking new knowledge) run parallel to sequencing strategies in the process of construction. The information search process involves using information, not merely locating it. Using information involves interpreting and creating meaning. No matter the amount or the quality of the information gathered, the problem is not solved until the information has been interpreted by the researcher. So, successful cognitive strategies are reflected in increased involvement with the process, while uncertainty in the information search process is reflected in a conservative approach to exploration of a topic.

The questions in the survey used an affective and physical measure as an indicator of the cognitive interactions taking place for teachers. While our teachers demonstrated a sound grasp of the cognitive strategies involved, what we also discovered was that over half (55.6\%) of our respondents prefer to stay with the sources of information with which they are comfortable, and will generally confine their search to the same types of information sources. This reflects the naive approach to sequence already commented on.

Search closure. The final stage of the search process culminates in a personalized synthesis of a research problem. There are different reasons for closing a search, revealing an inquiring or pragmatic approach. Diminishing relevance can lead to search closure, while enough information to achieve a purpose (whether or not all relevant information is at hand) may be regarded by some as 
the more pragmatic approach. In terms of an ideal method of learning, the former can be regarded as the more ideal approach for cognitive interaction with information. Creating new meaning in a research setting implies thorough analysis of existing knowledge.

Though teaching involves deadlines, as do professional studies and research, our teachers showed their academic background, with 74.3 percent favoring a thorough search for information, and 97.2 percent expressing a view that purpose is the deciding factor in search closure.

Mediator. Exploration is a key phase in formulating a focus during the search process. Inherent in the process is 'uncertainty' and the tension between process and product or new meaning, which places mediation as a process intervention into the information search process. Informationrelated mediation assists with access to information, while process-related mediation assists with learning from the use of information (Kuhlthau, 1993, p.134). The function of mediation is to provide control of sequence, pacing and direction in order to increase motivation and engagement in cognitive reflection and restructuring of knowledge.

Given that teachers deal with information and knowledge on a daily basis as part of their profession, it is useful to examine teachers' perceptions of the role of mediation. The Bethlehem study showed that while teachers like to discuss a research topic with others as a way of developing focus and pursuing their research, they are less likely to explore a topic with someone they believe has some prior knowledge of the focus for research and are even less interested in seeking mediation from a librarian.

These teachers' perspectives of the information search process seem to be one that does not strongly value the mediation available from information professionals. Kuhlthau noted similar disheartening findings in longitudinal studies of students' perception of a minimal role for librarians, and dissatisfaction expressed at the inadequate role that formal mediators played in their search process (Kuhlthau 1993, p. 76).

Sources of anxiety. That there is turmoil and uncertainty associated with the construction of meaning is understood. What we can also recognize is that teachers as a professional group belong to an era of change, with all to some degree or another having had to adapt to new technologies and new methods of accessing and retrieving information. The mounting pressure to know, analyze and decide in such an environment can evidence syndromes of technophobia and information anxiety. During the last decade, computers in the classroom have been followed by CD-ROM, and finally by the Internet.

Not surprisingly, the Bethlehem study showed that the newer the product, the greater the source of anxiety the product became in the information search process. While 61.1 percent were comfortable with computers, only 11.4 percent were comfortable using the Internet.

Generalized feelings and perceived skills. Overall, teachers operate in a professional environment that requires some regular need for information seeking in order to fulfill a personal professional or teaching requirement. Given that this will regularly involve use of library facilities, either at school or within the community, it is interesting to note the effect that interaction in such environments has in the overall affective dimension of their information search process, since these experiences form an intrinsic part of teachers perspectives of the information search process.

Being optimistic about search outcomes and feeling enthusiasm or frustration about interactions are affective skills that are integral to information states, stages and processes. The Bethlehem study indicated that teachers are optimistic when going to the library to carry out research and feel confident that they know how to use a library. They nevertheless find them to be frustrating places.

The relationship of this frustration to lack of confidence with technology would seem an obvious choice. However, frustration could also be the result of the instability and discrepancies already noted in the other phases of the mental model and the fact that teachers do not value the mediation offered by information professionals.

\section{Taking Teachers' Personal Perspectives of Information Literacy Into the Classroom}

As teacher librarians we acknowledge that students must be able to reflect on and elaborate their own ideas and those of their peers. The focus is on the student as the self-governed creator of meaning, with teachers acting as facilitator and mediator nurturing active cognitive abilities. An appropriate supportive environment includes traditional sources of information in the form of books, magazines, periodicals, newspapers and journals, audio and video, digital and communication 
magazines, periodicals, newspapers and journals, audio and video, digital and communication technology in the form of CD-ROM, online information services and databases, interactive audio and video, and hypermedia.

An information skills framework provides the cognitive scaffolding by providing a problemsolving model. Regardless of the framework used, the emphasis is on the recursive nature of the model and the physical, cognitive and affective phases of construction, as mentioned in the comments made about teachers' perspectives of the information search process.

While key concepts and understandings underlie different subject areas, it is the integration of process skills that make learning possible. Stripling (1995) suggests that the mental model of the inquiry (or information search) process of the teacher is central to successful outcomes for students' learning.

Teachers are responsible for creating a learning environment for their students and should be acting as mediators for students involved in the information search process. Teachers are constructing this environment based on their teacher training, teaching experience, professional development experiences, and in discussion with colleagues along the way.

The piece of the equation that we teacher librarians have not taken so much into account is the possibility that these teachers are also constructing this environment based on their own personal perspective of the information search process and construction of meaning, which we find is reflected in their own thinking and behavior in problem-solving and research for themselves.

What is the relationship between this personal construct, and teachers' perspectives of the phases of information construction expected of students?

The Bethlehem study asked teachers to describe their preferences for the information search behavior for students in their classes, and these responses were paired or matched with questions related to their own personal construct.

These are the salient features which this comparison revealed. Overall, these teachers:

- preferred students to begin the information search process with a clear focus in mind ;

- did not acknowledge the uncertainty and confusion which accompanies information seeking;

- preferred that students' took detailed notes, printed or photocopied sources of information;

- preferred that the teacher librarian provide direction in locating material, rather than the teacher;

- expected the computer catalogue to be the main access point for information;

- preferred that students use varied sources of information;

- recognized the important role of mediation offered by teachers, teacher-librarians, parents and others;

- expected students to be more interested in a topic as information is gathered;

- showed a narrow approach to the facilitation of motivation, with one third still relying on a didactic model of information transfer.

An analysis in your own school setting may well come up with a different list of preferred behaviors. However, what the Bethlehem study has shown, is that these teachers' phases of construction in the information search process are strongly reflected in the phases of construction expected of their students. This includes both the strengths and weaknesses in the construct. In the areas where weaknesses in the personal construct do not carry through, such as in the vital role of mediation in the identification and exploration of a research topic, it may be that this is because the general principles of education have overridden the inadequate personal construct, by accepting a student as being a cognitive apprentice and one therefore who does not have the necessary skills to operate successfully alone.

\section{Matching Expectations for a Multi-Faceted Approach to Information Seeking}

Given that information seeking is fundamentally a problem-solving and interactive process, it is interesting to consider teachers' perceptions of the place of information and technology in the teaching-learning continuum. Just how do teachers' awareness and confidence with a range of 
information sources compare to teachers' view of the importance of those same sources for the information needs of their students?

Cross-tabulation of an extensive list of questions related to all things technological (video conference, online, automated catalogues etc.), magazines, newspapers, video programs, and reference and nonfiction books, showed considerable disparity between traditional sources of information, such as videos or dictionaries, compared to newer sources such as Internet or CD-ROM. Whereas a source such as video shows a closer relationship between teachers' perceived level of importance for students and level of personal confidence with technology, newer items may well be perceived as being important for students, even when teachers are insecure or very insecure in the use of the information source.

While this finding may confirm our suspicions, this need not be interpreted as a negative finding. What it does is confirm that the change to use of newer technology is slow to take place. It also confirms that the desire to learn new behavior precedes the change, if we interpret the learning expectations for students as a recognition of a shift and a desire to learn a new behavior.

Electronic digital information seeking is new, and for many, complicated to learn. Skill transfer from traditional sources needs to take place, yet the transfer is not automatic. The Bethlehem study confirms that a multifaceted approach to information seeking is now a part of the agenda for schools and the teaching-learning continuum. However, it also confirms that teachers' expertise and zone of comfort with that approach is not.

\section{IMPLICATIONS FOR PROFESSIONAL PRACTICE}

There are many externally imposed influences on the interactions taking place in the classroom. However, our work at Bethlehem College has shown that some formal consideration now also needs to be given to the significance of teachers' personal perspectives of the information search process, and the impact or influence of these perspectives on the pedagogy of the classroom.

Our particular group of teachers showed that they are unclear about the nature and purpose of focus formulation, and its relationship to physical and cognitive stages in the information process. They also showed that the sequence of actions and the recursive nature of information seeking is also not clearly understood.

Exactly where clarity is needed, personal perspectives seem to be confounding the process. Hidden assumptions about teachers' familiarity with the process and their consequent ability to act as mentors is exposed, and shows a clear area for action.

Likewise our teachers exhibited clear zones of comfort and discomfort with use of a wide range of sources of information for their classroom teaching. While they can and do recognize the importance of newer sources, they also acknowledge that they are unable to use the sources well and are unable to model good practice for their students.

Given this scenario, it should not seem unusual to me, as teacher librarian in the school, to find some teachers liking independent lessons in information literacy and separate teaching of information skills isolated from the subject content. If I am surprised it is clearly because my training and my perspective are vastly different from theirs. The outcome is often not to my liking. For example, with this disparity in teacher's mental models comes a focus that is still very much on consolidation of information for end-product marking. If understanding of the stages of the information process is unsound, teachers cannot design effective means for process assessment. Changing this is never straightforward.

The significant implication is that while teachers continue to have a poor understanding of what skills and behaviors are associated with information literacy, the more likely they are to assume that their students are learning information skills somewhere else.

Discussion in the interviews with key Faculty Coordinators strengthened interpretation that disparity is one of the major hurdles that must addressed. For example, while one Faculty Coordinator was able to talk extensively about skills and strategies as part of information literacy and the vital role of teacher as mediator, another Faculty Coordinator, at the other end of the spectrum, could not articulate information skills strategies or methods of integration into the curriculum. For her, a computer epitomized information access and information skills. The faculty leaders alone, demonstrated the range and depth of disparity in classroom pedagogy. What they also demonstrated, unfortunately all too well, was the lack of a whole-school approach to the essential task of developing 
good practice in education programs, with a cross-curricular approach, and making full use of varied bibliographic and technological sources of information.

The implications for professional development are clear. In fact, most education authorities are active in devising ways to address these needs, particularly in the area of new technology. What is possibly of more concern is the nature of professional development activities. I challenge you to return to your schools and analyze the design of professional inservice or update programs. To what extent do these programs, however valid and seemingly successful, nevertheless offer a set of skills or competencies that are overlaid on what a teacher has been already doing. Though a teacher may wholeheartedly accept a new challenge and embrace a new way of teaching - to what extent is the change impeded by existing personal construct, which has not been articulated, explored, and examined for the disparity it carries?

Is this why, despite years of proactive work by teacher librarians, we still have e-mail listservs that constantly have questions posted to the TL community which essentially ask: "How can I convince, encourage, or get onside my year X classroom teacher to try out information skills"? "What programs have you found successful?" "What strategy worked well?" and so on.

\section{IMPLICATIONS FOR EDUCATION}

We know that learning for students needs to be staged so that learners can build the multiple skills required to achieve expert performance and discover the conditions under which they apply. A sound model of the information process provides these learning anchors, within an organizational framework, for the control of sequence, pacing and direction, and to provide motivation and facilitate engagement in cognitive reflection and the restructuring of information and knowledge. In this framework a teacher becomes both expert and peer, working alongside the student as co-learner and co-investigator. To be successful in this role teachers must radiate information literacy. To do this they need a sound mental model of the information seeking process in order to model good practice in education programs and to act effectively as mediator for each student or for the class.

Yet in the process of information seeking for learning, teachers' perspectives of the information search process may indeed have a significant negative impact on the learning of students. Examine these relationships in your school, complex as they may be, in order to minimize any negative impact.

The matter carries a sense of urgency when we consider students' natural processes of learning within complex information environments. While our teachers are mismatched to our students in expertise with technology we are not only losing our ability engage our students beyond mere entertainment or simplistic information gathering, but we are also missing the opportunity to bend technologies to a pedagogical purpose.

What is an even more critical consideration is the fact that integration of technology into the curriculum involves integration of a medium that comes with its own forms of discourse. Students may be beginning to grasp this ahead of teachers. Yet many teachers are insecure and certainly have not had curriculum or education-based training in these fields.

Electronic information environments are changing the way we access and use information and changing the strategies we use to do so successfully. If education is designed to teach students to know how to learn, including in new fields, the ability to seek new knowledge in new fields so as to reconfigure knowledge already possessed must be developed and refined, and embedded in an appropriate mental construct of the information search process.

\section{CONCLUSION}

It is time to evaluate and articulate teachers' own mental construct. What do our teachers need to know differently about information literacy in order to facilitate independent learning within the curriculum so as to foster development of lifelong learning skills?

Since teachers are acting as mediators they need to be shown how to use information-related strategies to teach problem solving and learning more effectively. While information professionals may consider that this is exactly what they have been doing for some years now, a key factor that has been overlooked has been the personal construct or mental model that a teacher brings to the equation. Professional development must be designed to help teachers clarify their personal 
perspectives and competencies with information seeking and the information search process. Likewise, initiatives related to the introduction of new technologies need to focus not just on the mechanics of information access and possible methods of integration into the classroom, but also on the conceptual demands of information access and communication within these environments.

\section{REFERENCES}

Australian School Library Association \& Australian Library and Information Association. (1993). Learning for the future: Developing information services in Australian schools. Carlton: Curriculum Corporation.

Eisenber, M. \& Brown, M. (1992). Current themes regarding library and information skills instruction: Research supporting and research lacking. School Library Media Quarterly, 20(2), 103-109.

Kuhlthau, C.C. (1993). Seeking meaning: A process approach to library and information services. Norwood, NJ: Ablex.

Liesener, J.W. (1985). Learning at risk: School library media programs in an information world. School Library Media Quarterly, 14(1), 11-20.

Rogers, R. (1994). Teaching information skills: A review of the research and its impact on education. London: British Library Research.

Stripling, B.K. \& Pitts, J.M. (1988). Brainstorms and blueprints. Englewood, CO: Libraries Unlimited.

Stripling, B. K. (1995). Learning-centred libraries: Implication for research. School Library Media Quarterly, 23(3), 163-170. 